\title{
Influence of the oxidation of GaAs on the work of light-emitting spintronic diodes with InGaAs/GaAs quantum wells
}

\author{
S. Saeid \\ Lobachevsky State University of Nizhni Novgorod, 23 Gagarin Avenue, \\ Nizhny Novgorod, 603950, Russia \\ s.saeed34@yahoo.com
}

PACS 72.25.-b, 72.25.Ba, 72.25.Hg, 75.47.-m DOI 10.17586/2220-8054-2015-6-6-875-881

\begin{abstract}
A study of oxygen atoms' interactions on a GaAs (001) structure surface shows that these atoms are getting adsorbed onto the surface, form an oxide layer, and over time its thickness increases. This oxide layer hinders the injection of electrons and the holes from the metal layer to the semiconductor, thus affecting the photoelectroluminescence and the work of Metal-oxide-semiconductor diodes. These studies also examine the growth rate of oxide layers on the surface of the structure with different deposition degrees $\left(400{ }^{\circ} \mathrm{C}, 630{ }^{\circ} \mathrm{C}\right)$ of cover layers and the extent of the oxygen atoms' penetration into the structure.
\end{abstract}

Keywords: tunnel effect, spin injector, metal-oxide-semiconductor diodes, oxides of GaAs, storage time, diffusion penetration.

Received: 13 October 2015

Revised: 30 October 2015

\section{Introduction}

Metal-oxide-semiconductor diodes and transistors are considered as essential components of an advanced electronic device. The formation of an oxide layer on the semiconductor structure's surface may cause some difficulties in the preparation of such elements since the thickness of the oxide layer is time dependent. So it is necessary to treat the semiconductor surface before the insulator and metal deposition.

In this work, the influence of storage time on the surface of gallium arsenide is explored. The storage time (1 year) creates a difference in the growth rates for oxide layers on stored wafer surfaces over those which were 'freshly-processed', both with two different deposition temperatures of $400{ }^{\circ} \mathrm{C}$ and $630{ }^{\circ} \mathrm{C}$.

Also the comparison of the oxide layer formed on the surface of the structure and $\mathrm{Al}_{2} \mathrm{O}_{3}$ layer is performed, revealing the fact that although the oxide thickness slightly increases over time, the chemical bonding of the uppermost surface layers remains in an unstable condition [1]. It means that the steps used to prepare GaAs surfaces can have a profound effect on the diode manufacturing process.

The elimination of contaminants and oxide which are present on the GaAs surface can be simply accomplished by etching and degreasing. Degreasing is achieved with acetone and ethanol [2]. The etching process can be performed by several dry and wet methods. Various solutions, such as $\mathrm{H}_{2} \mathrm{O}_{2} / \mathrm{NH}_{4} \mathrm{OH} / \mathrm{H}_{2} \mathrm{O}$ [3], $\mathrm{H}_{2} \mathrm{SO}_{4} / \mathrm{H}_{2} \mathrm{O}_{2} / \mathrm{H}_{2} \mathrm{O}[4,5], \mathrm{HCl} / \mathrm{H}_{2} \mathrm{O}$ [6], or $\mathrm{H}_{2} \mathrm{SO}_{4} / \mathrm{H}_{2} \mathrm{O}_{2} / \mathrm{HCl}$ [7], are used for wet-etching.

The oxidation products of GaAs are the following oxides: $\mathrm{Ga}_{2} \mathrm{O}_{3}$ and $\mathrm{As}_{2} \mathrm{O}_{3}$ [8]. The As oxide is highly soluble in oxygenated water, so, that fact gives one an opportunity to remove 
it from the GaAs surface photochemically [8]. The aqueous solutions of hydrofluoric acid are used to remove surface oxides [2], and to passivate GaAs surface either sulfide or gallium oxide can be applied to the oxidized GaAs surface [8].

\section{Experimental}

Semiconductor/metal structures with substrates of n-GaAs (001) were grown under atmospheric pressure of hydrogen using metallo-organic chemical vapor deposition (MOCVD) for the semiconductor part. For the tunnel barrier/ferromagnetic metal part, they were grown in vacuum [9] using electron-beam evaporation.

The structures contain three quantum wells (QWs) with different contents of In $x=0.25$, 0.20 and 0.15 which are located at different depths 30, 70, and $110 \mathrm{~nm}$ from the surface respectively. The temperature during deposition of the cover layer with the thickness up to 30 $\mathrm{nm}$ was $400{ }^{\circ} \mathrm{C}$ for the first structure, and $630{ }^{\circ} \mathrm{C}$ - for the second structure. The data obtained in the investigation of the structure was confirmed on cross-sectional samples using transmission electron microscopy (JEM-2100F).

At this point, electro-photoluminescence is measured. Impurities and the distribution of components were analyzed at the cross-sectional structure with the help of Energy dispersive X-ray spectroscopy (EDS), integrated in the electron microscope. The PL was excited by $\mathrm{He}-\mathrm{Ne}$ laser with power of $30 \mathrm{~mW}$, and spectra were recorded at $77 \mathrm{~K}$.

The Co layer was deposited directly on 'freshly-processed' wafer surfaces and on the wafer surfaces with 1 year of storage time with different deposition temperatures $\left(400{ }^{\circ} \mathrm{C}\right.$, $630{ }^{\circ} \mathrm{C}$ ) of cover layers.

\section{Results and discussion}

Figure 1 shows that the photoluminescence spectra of the structure with Co layer deposited on the structure's surface right after sample preparation (curve 4) differ from the photoluminescence spectra of the structure with the Co layer deposited on the sample with 1 year of storage time (curve 3). The temperature during these depositions was $400^{\circ} \mathrm{C}$. The difference of the photoluminescence spectra comes from the formation of oxide layer on the structure's surface.

Curve 4 reflects the complete quenching of photoluminescence in 1 st, 2nd and $3 \mathrm{~d}$ QWs. This quenching comes from Co atoms penetrating into 3 QWs $(110-130 \mathrm{~nm})$ and diffusing inside the structure. The diffusion of $\mathrm{Co}$ atoms leads to the formation of nonradiative recombination centers (defects) which hinder the process of radiation emission (electrophotoluminescence).

Curve 3 shows that, the oxide layer on the surface of the structure becomes a barrier which prevents the diffusion penetration of Co atoms into QWs $(20-40 \mathrm{~nm})$ in the structure. Thus the intensity of photoluminescence has not practically changed after deposition of the Co layer.

Curve 2 and 3 point out that PL peaks at $1.280,1.332$ and $1.385 \mathrm{eV}$, which correspond to the energies of the basic transitions in QWs with $x=0.25,0.20$ and 0.15 , have shifted from their places to $1.283,1.342$ and $1.391 \mathrm{eV}$. This shift (i.e. change of the wavelengths) happens due to diffusion penetration of $\mathrm{O}$ atoms into QWs $(120-140 \mathrm{~nm})$ of the structure and due to formation of new energy levels within the QWs. The energy levels appear from the influence of indium atom concentration in QWs.

In Fig. 2, curve 4 shows that Co penetrates into 2 QWs on the depth of $80-100 \mathrm{~nm}$ and diffuses inside the structure. The temperature during this deposition was $630{ }^{\circ} \mathrm{C}$. Curve 3 indicates that a decrease in intensity of radiation for the first PL peak is larger than a decrease 


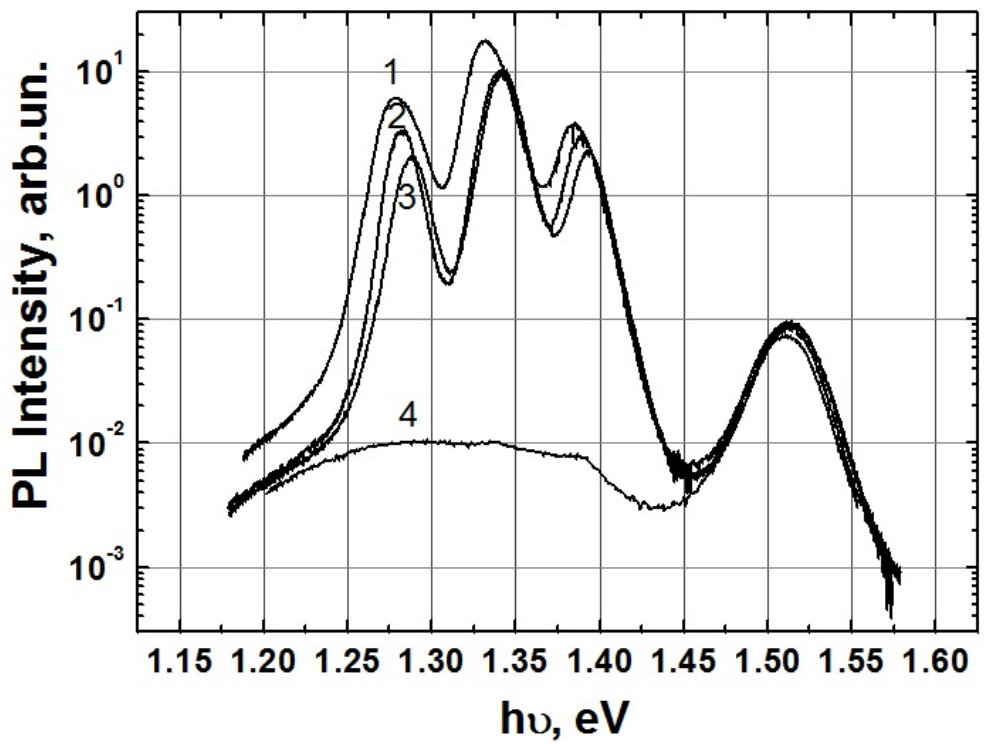

FIG. 1. The photoluminescence spectra of the structure with three quantum wells and with a low deposition degree $\left(400{ }^{\circ} \mathrm{C}\right)$ of cover layer: 1 - initial sample; 2 initial sample in a year; 3 - after deposition of Co in a year; 4 - after deposition of Co

shown in Fig. 1 curve 3. It means that the Co atoms penetrate deeper into the structure and that's why they form a larger number of defects across the diffusion barrier in the QW-1(Fig. 1, curve 3), than a number of defects formed in the QW-1 (Fig. 2, curve 3). It is evident that the oxide layer formed on the surface of the sample becomes a diffusion barrier. The thickness of the oxide layer on the surface of the structure deposited at the low temperature $\left(400{ }^{\circ} \mathrm{C}\right)$ is larger than the thickness of the oxide layer on the surface of the structure deposited at high temperature $\left(630{ }^{\circ} \mathrm{C}\right)$, thus the oxidation speed is higher. It means that the temperature during the deposition of the cover layer plays a major role in reducing the oxidation rate.

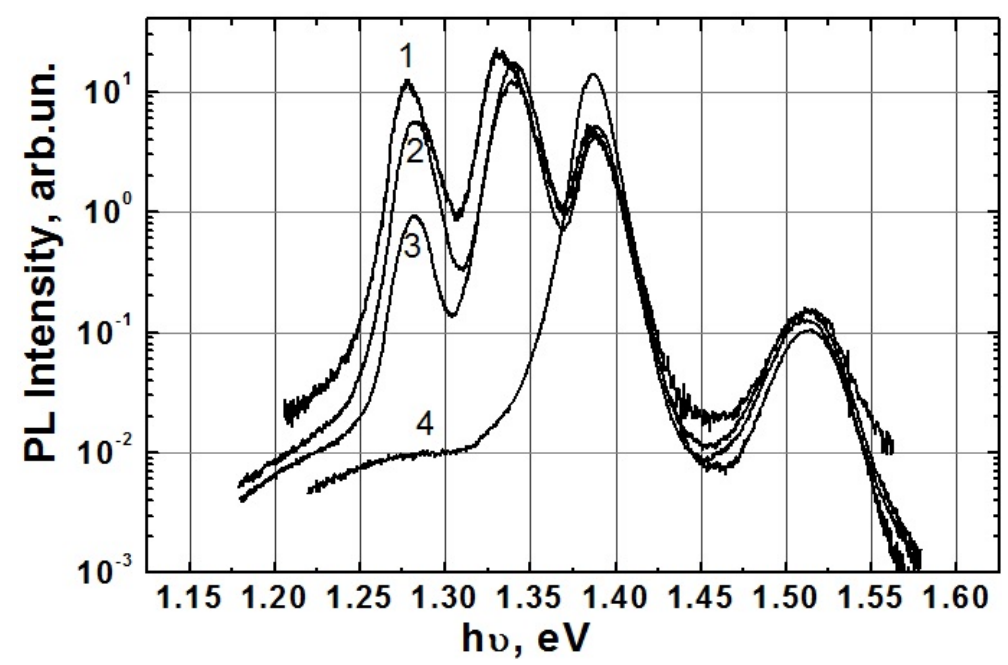

FIG. 2. The photoluminescence spectra of the structure with three quantum wells and with a high deposition degree $\left(630^{\circ} \mathrm{C}\right)$ of cover layer: 1 - initial sample; 2 initial sample in a year; 3 - after deposition of Co in a year; 4 - after deposition of Co 
Figure 3 reveals the fact that $\mathrm{A} 12 \mathrm{O} 3$ insulator layer $(1.2 \mathrm{~nm})$ deposited on the oxide layer $(1.1 \mathrm{~nm}$ to $1.3 \mathrm{~nm})$ prevents diffusion penetration of Co. Thus PL spectrum remains practically unchanged, but the tunnel effect disappears as the thickness of the insulator becomes about $2.5 \mathrm{~nm}$. The crystal structures of both oxides are different from each other as shown in Fig. 4.

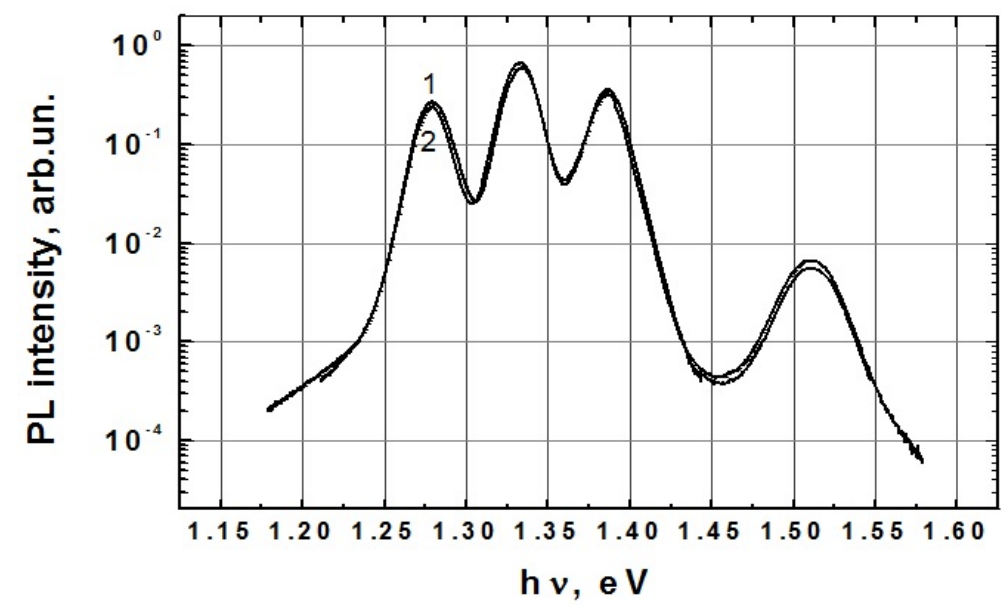

FIG. 3. The photoluminescence spectra of the structure with three quantum wells: 1 - initial sample; 2 - deposition of $\mathrm{Al}_{2} \mathrm{O}_{3}(1.2 \mathrm{~nm}) / \mathrm{Co}$ on oxide layer (in a year)

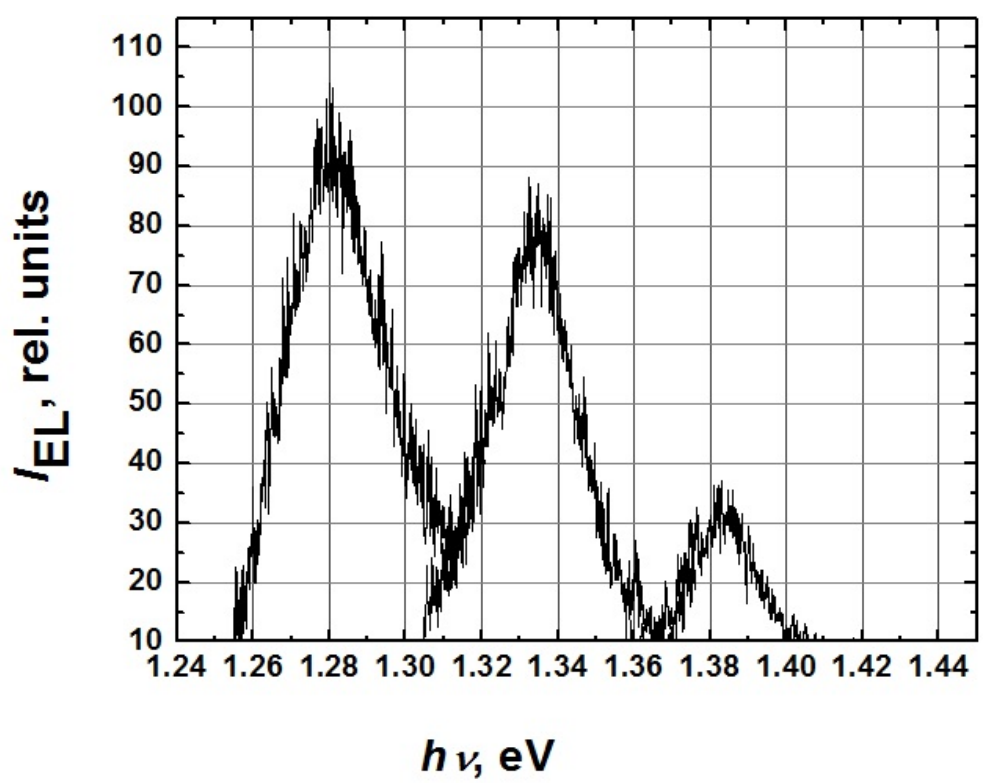

FIG. 4. The electroluminescence spectra of the structure with three quantum wells with oxide layer (in a year) and $\mathrm{Al}_{2} \mathrm{O}_{3}(1.2 \mathrm{~nm}) / \mathrm{Co}$ layer

From Figs. 5 and 6, it is clear that the thickness of the oxide layer formed on the surface of the structure after a year is approximately $1.1-1.3 \mathrm{~nm}$. Although, comparing to the quality of $\mathrm{Al}_{2} \mathrm{O}_{3}$, the quality of oxide insulator, is lower due to the large amount of defects formed in the interface.

Figures 5 and 6 show that the diode with cover layer deposited at low temperature of $400{ }^{\circ} \mathrm{C}$ and with $1 \mathrm{~nm}$ of $\mathrm{Al}_{2} \mathrm{O}_{3}$ begins emitting radiation by the current up to $2 \mathrm{~mA}$ while 
Influence of the oxidation of GaAs on the work of light-emitting spintronic diodes ...

the diode with oxide needs the current up to $30 \mathrm{~mA}$ just for the start. It leads to loss of extra amount of energy without any yield. This indicates that the oxide layer plays a less efficient role as a tunneling and diffusion barrier than $\mathrm{Al}_{2} \mathrm{O}_{3}$.

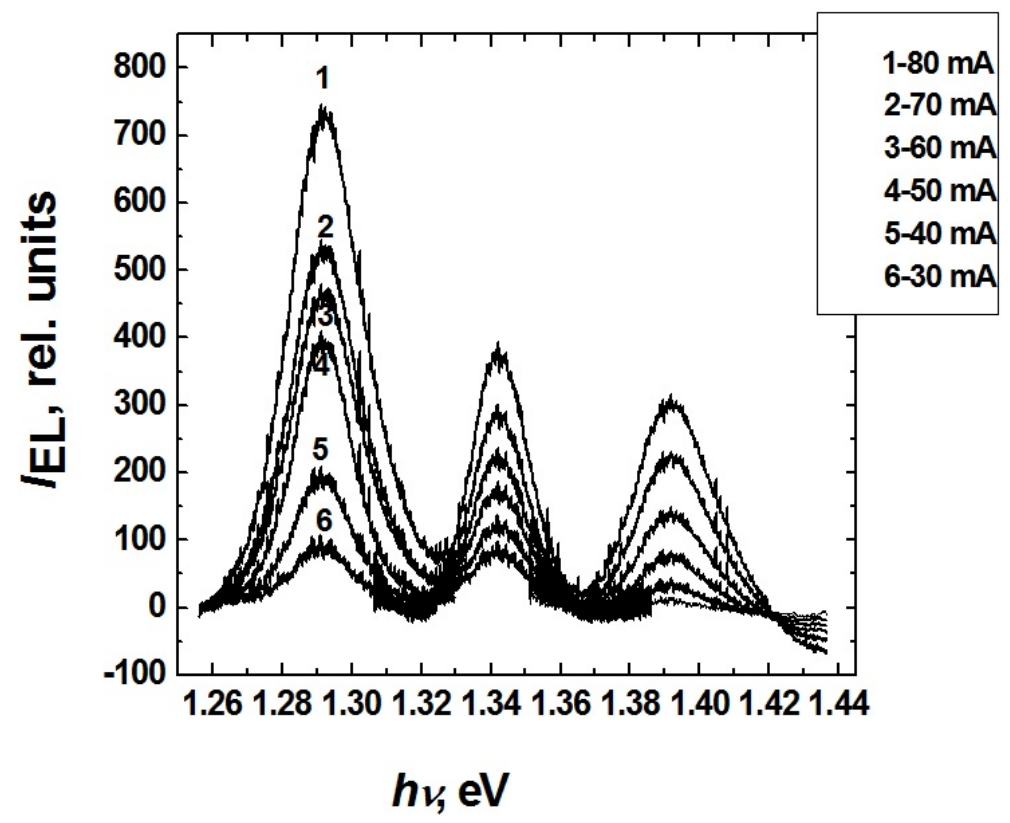

FIG. 5. The electroluminescence spectra of the structure with three quantum wells and a low deposition degree $\left(400^{\circ} \mathrm{C}\right)$ of cover layer with oxide layer (in a year) and Co layer

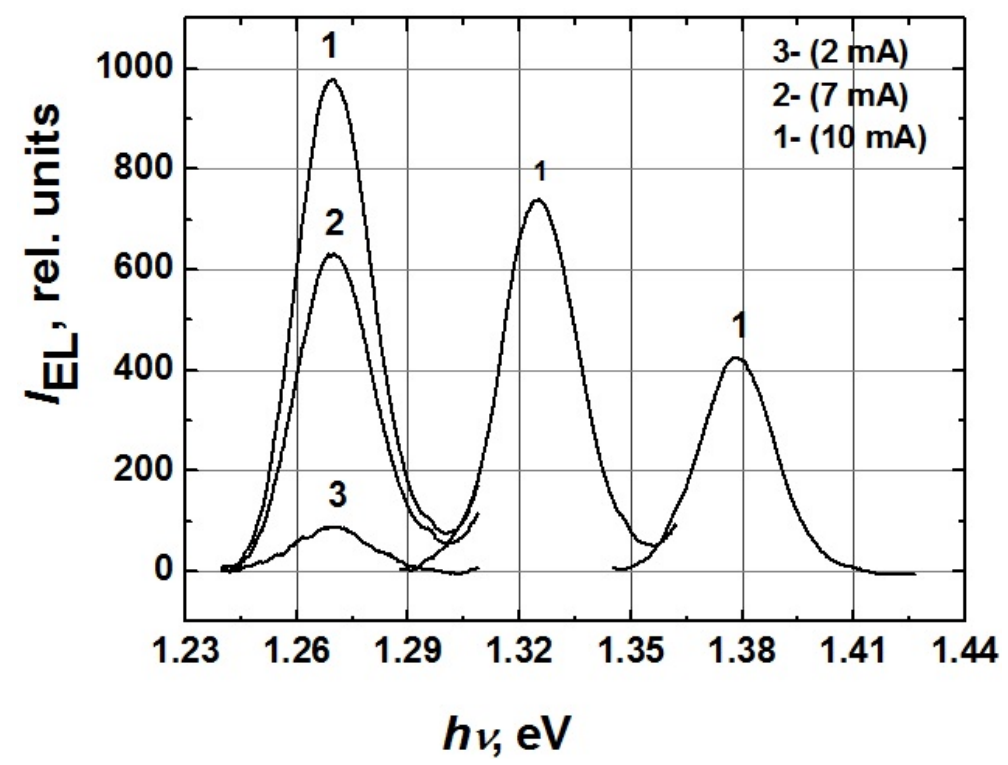

FIG. 6. The electroluminescence spectra of the structure with three quantum wells with $\mathrm{Al}_{2} \mathrm{O}_{3}(1 \mathrm{~nm}) /$ Co layers

Figure 7 confirms that $\mathrm{O}$ atoms penetrate into the structure but their concentration does not exceed $2 \%$. Also, Co atoms penetrate into $\mathrm{Al}_{2} \mathrm{O}_{3}$ and $\mathrm{Au}$ layers, and atoms of $\mathrm{Al}, \mathrm{O}$ and $\mathrm{Au}$ penetrate into Co layer. Noticeably, the ratio of $\mathrm{O}$ atoms to $\mathrm{Al}$ atoms at the $\mathrm{Al}_{2} \mathrm{O}_{3}$ layer is $45 / 15$ while in fact it should be $3 / 2$. This is evidence for the oxide layer's presence. 
Figure 8 shows that the resistance increases when an oxide layer is formed on the surface of the structure and this increase depends on the thickness of this oxide layer. The Schottky barrier height is $0.85 \mathrm{eV}$, however, after a year, it becomes $0.86 \mathrm{eV}$.

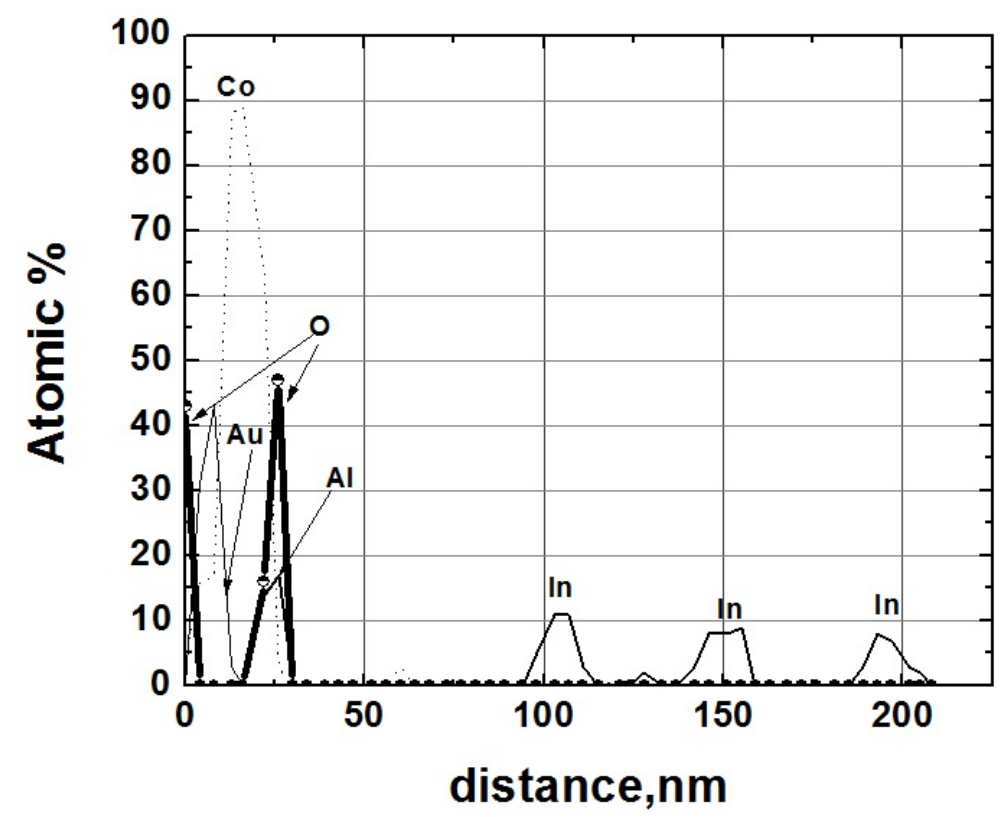

FIG. 7. Concentration profiles of the elements in the depth of the structure with three quantum wells and with deposition temperature of the cover layer at $400{ }^{\circ} \mathrm{C}$ and $\mathrm{Al}_{2} \mathrm{O}_{3} /$ Co layers

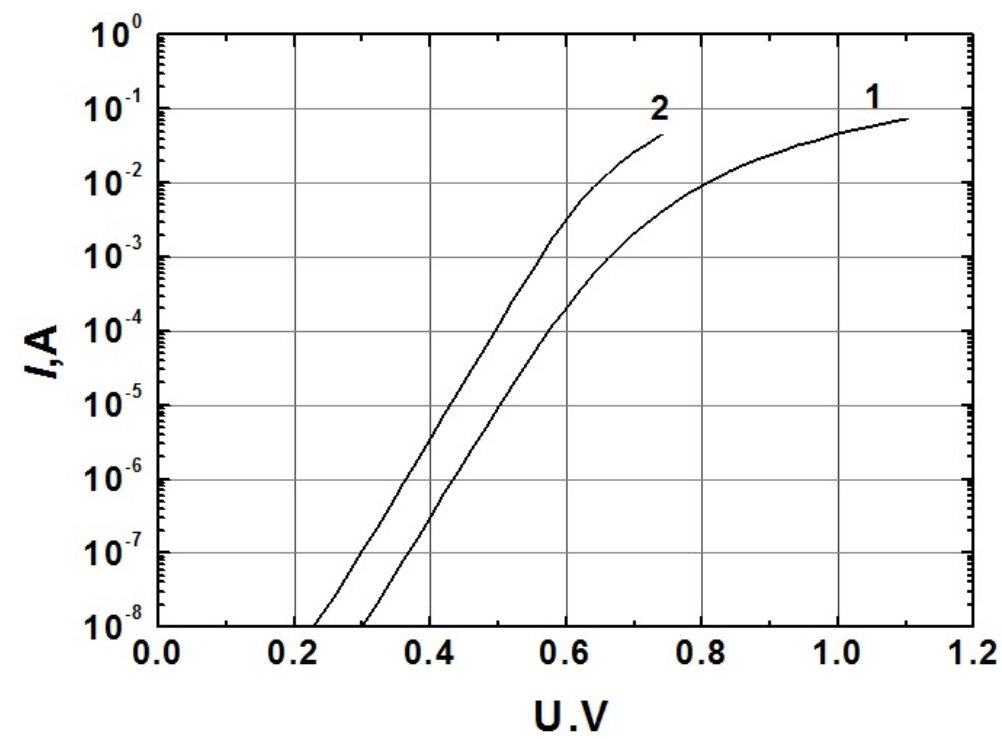

FIG. 8. The current-voltage characteristics of diode: 1 - with an oxide layer on the surface of the structure; 2 - without any oxide layer 


\section{Conclusions}

In summary, the thickness of an oxide layer can have negative and positive impacts on the injection of a charged carrier. If the thickness of the oxide layer is more than $1 \mathrm{~nm}$, the resistance in the structure and the amount of defects on its interface increase, which leads to reduction of radiation intensity emitted from the structures, and energy loss; if the thickness of the oxide layer is less than $0.7 \mathrm{~nm}$, it prevents the penetration of metal atoms into the structures and increases possibility of electron transmission via a tunneling mechanism.

\section{References}

[1] Th. Mirandi, D.J. Carlson. The Effects of Chemical Treatment and Storage Time on the Surface Chemistry of Semi-Insulating Gallium Arsenide. Proceeding of 'CS MANTECH Conference', 2009, Tampa, Florida, USA, May 18th-21st.

[2] Köhler M. Etching in Microsystem Technology (1st edn.) Wiley-VCH: Weinheim, 1999.

[3] J.S. Song, Y.C. Choi, et al. Wet chemical cleaning process of GaAs substrate for ready-to-use. J. Cryst. Growth, 2004, 264 (98), P. 98-103.

[4] H.C. Liu, S.H. Tsai, J.W. Hsu, H.C. Shih. The phase identification of the H2SO4-etched GaAs by X-ray diffraction. Mat. Chem. Phys., 1999, 61 (2), P. 117-123.

[5] A. Munoz-Yague, J. Piqueras, N.J. Fabre. Preparation of Carbon-Free GaAs Surfaces: AES and RHEED Analysis. Electrochem. Soc., 1981, 128 (1), P. 149-153.

[6] K. Matsushita, S. Miyazaki, S. Okuyama, Y. Kumagai. Observation of HCl-and HF-Treated GaAs Surfaces by Measuring Contact Angles of Water Droplets. Jpn. J. Appl. Phys., 1994, 33 (8), P. 4576-4580.

[7] Z.H. Lu, C. Lagarde, et al. A surface analytical study of GaAs (100) cleaning procedures. J. Vac. Sci. Technol. A, 1989, 7 (3), P. 646-650.

[8] W. Wang, G. Lee, et al. First-principles study of GaA(001)-beta2(2X4) surface oxidation and passivation with H, Cl, S, F, and GaO. J. Appl. Phys., 2010, 107, P. 103720.

[9] B.N. Zvonkov, O.V. Vikhrova, et al. Using laser sputtering to obtain semiconductor nanoheterostructure. $J$. Opt. Tech., 2008, 75 (6), P. 389-393. 